\title{
An Alternative to Carbon Additives: The Fabrication of Conductive Layers Enabled by Soluble Conducting Polymer Precursors - A Case Study for Organic Batteries
}

\author{
Christian Strietzel, ${ }^{\dagger}$ Kouki Oka, ${ }^{\dagger}$ Maria Strømme, Rikard Emanuelsson, ${ }^{*}$ and Martin Sjödin*
}

Cite This: ACS Appl. Mater. Interfaces 2021, 13, 5349-5356

Read Online

\section{ACCESS | Lill Metrics \& More | 期 Article Recommendations | S1 Supporting Information}

ABSTRACT: Utilizing organic redox-active materials as electrodes is a promising strategy to enable innovative battery designs with low environmental footprint during production, which can be hard to achieve with traditional inorganic materials. Most electrode compositions, organic or inorganic, require binders for adhesion and conducting additives to enable charge transfer through the electrode, in addition to the redox-active material. Depending on the redox-active material, many types and combinations of binders and conducting additives have been considered. We designed a conducting polymer (CP), with a soluble, trimeric unit based on 3,4-ethylenedioxythiophene (E) and 3,4-propylenedioxythiophene (P) as the repeat unit, acting as a combined binder and conducting additive. While CPs as additives have been explored earlier, in the current work, the use of a trimeric precursor enables solution processing together with the organic redoxactive material. To evaluate this concept, the CP was blended with a redox polymer (RP), which contained a naphthoquinone (NQ) redox group at different ratios. The highest capacity for the total weight of the $\mathrm{CP} / \mathrm{RP}$ electrode was $77 \mathrm{mAh} / \mathrm{g}$ at $1 \mathrm{C}$ in the case of $30 \% \mathrm{EPE}$ and $70 \%$ naphthoquinone-substituted poly(allylamine) (PNQ), which is $70 \%$ of the theoretical capacity given by the RP in the electrode. We further used this electrode in an aqueous battery, with a $\mathrm{MnSO}_{4}$ cathode. The battery displayed a voltage of $0.95 \mathrm{~V}$, retaining $93 \%$ of the initial capacity even after 500 cycles at $1 \mathrm{C}$. The strategy of using a solution-processable CP precursor opens up for new organic battery designs and facile evaluation of RPs in such.

KEYWORDS: redox-active polymer, organic electrode, organic battery, quinones, conducting polymers, conductivity additives

\section{INTRODUCTION}

The push for an environmentally sustainable society has created a huge demand for new and sustainable battery technologies. ${ }^{1,2}$ Batteries based on organic redox-active materials are receiving substantial attention in the research community. $^{3-5}$ These types of materials enable new and interesting designs thanks to the synthetic possibilities that come with using organic materials that can be produced in low-temperature processes from abundant resources. ${ }^{6,7}$ These types of materials are therefore considered environmentally benign compared to inorganic materials in conventional lithium ion or nickel metal hydride batteries requiring hightemperature processes during production and the use of limited resourses. 3,7

Various organic battery designs have been presented, ranging from the pioneering work of Nishide et al. ${ }^{6,8}$ and Poizot et al. ${ }^{9}$ to the more recent all-organic batteries and hybrid-organic batteries. ${ }^{10-13}$ These batteries require conducting additives (and binders for adhesion) in the electrode formulation since the organic redox-active materials themselves do not supply sufficient conductivity. In most cases, carbon blacks, carbon nanofibers, ${ }^{14,15}$ carbon nanotubes, ${ }^{16,17}$ or carbon cloths ${ }^{12}$ are used in a substantial amount (20-80\%) in the electrode composition. In a different approach, we showed that using a conducting polymer (CP) backbone with redox pendent groups could result in all-organic ${ }^{18-22}$ or hybrid-organic electrode materials without the use of carbon additives since the necessary conductivity was supplied by the CP backbone. ${ }^{23,24}$

In the present work, we investigate if it may be possible to use the CP backbone directly as a conducting additive, together with a non-conducting redox polymer (RP). Our hypothesis was that, if such an additive was soluble, then a solution with the dissolved RP could be formed during processing and that this solution easily could be deposited on an electrode resulting in an optimal $\mathrm{CP} / \mathrm{RP}$ blend. Inganäs et

Received: December 21, 2020

Accepted: January 12, 2021

Published: January 22, 2021 
al. have shown a variety of concepts using CPs, i.e., polypyrrole or poly(3,4-ethylenedioxythiophene) (PEDOT) as conducting and binder additives together with the biopolymer lignin. In their work, polymerization, either electrochemically, forming a film, or chemically, resulting in a suspension, formed composites between the $\mathrm{CP}$ and the $\mathrm{RP} .{ }^{25-28} \mathrm{~A}$ drawback of the reported approaches is that a monomeric starting material for the CP is used, which has to be polymerized from solution. Mixing the $\mathrm{CP}$ and the RP in solution and depositing the blend on an electrode in its dissolved form are thus not possible. Composites containing CPs and inorganic redox materials, such as lithium ion battery cathodes, have also been explored. For example, using a suspension of PEDOT:PSS together with the typical formulation used for lithium ion cathode materials, with lithium iron phosphate as the active component, results in improved rate capabilities. ${ }^{29,30}$ Although PEDOT:PSS can be solution-processed, it is truly a suspension, which is why it cannot be considered a soluble conducting additive.

Instead of exploring these common paths of creating a composite in which a $\mathrm{CP}$ has binder and conducting properties, we choose to further study post-deposition polymerization, where a precursor for a $\mathrm{CP}$ in the form of a trimer is deposited on the electrode and subsequently polymerized in situ. This way, the conducting additive is soluble and can be solution-processed together with the RP. Ideally, the conducting additive should be soluble in the same solvent as the $\mathrm{RP}$, which could be a wide range of organic solvents, allowing processing and deposition on the electrode while being insoluble in the solvent that is used as the electrolyte. In this study, we focus on naphthoquinone (NQ) $\mathrm{RPs}$ to create a $\mathrm{CP} / \mathrm{RP}$ composite. This composite polymer shares the same redox-active group as the conducting $\mathrm{RP}$ where the naphthoquinone (NQ) redox-active group is covalently bound to a thiophene backbone (EP(NQ)E) on which we reported earlier. ${ }^{22}$ We therefore chose $\mathrm{EP}(\mathrm{NQ}) \mathrm{E}$ as a reference material for the present study. To further explore the potential of the formed $\mathrm{CP} / \mathrm{RP}$ composite polymer, we used the electrode as an anode in a hybrid organic battery with $\mathrm{MnO}_{2} / \mathrm{Mn}^{2+}$ as the cathode.

\section{EXPERIMENTAL SECTION}

2.1. Materials. All solvents and chemicals were purchased from Sigma-Aldrich and were used without further purifications unless otherwise specified. Deionized water was used to prepare aqueous electrolytes.

2.2. Polymer and Trimer Synthesis. PNQ was prepared, as lined out in an earlier work. ${ }^{31}$ Shortly, 2-bromo-1,4-naphthoquinone dissolved in anhydrous dimethylformamide (DMF) was added to a water solution of poly(allylamine) $\left(M_{\mathrm{w}}=1600\right)(15 \mathrm{wt} \%)$ and stirred for $24 \mathrm{~h}$ at $25{ }^{\circ} \mathrm{C}$ (Scheme S1). For precipitation, the reaction mixture was poured into acetone to yield a red powder after washing. The polymer was characterized to be PNQ using ${ }^{1} \mathrm{H}-\mathrm{NMR}$ spectroscopy (Figures $\mathrm{S} 1$ and S2): ${ }^{1} \mathrm{H}-\mathrm{NMR}\left(500 \mathrm{MHz},\left(\mathrm{CD}_{3}\right)_{2} \mathrm{SO}, \delta \mathrm{ppm}\right): 0.3-$ $2.4\left(\mathrm{CH}_{2}, \mathrm{NH}_{2}\right.$ (poly(allylamine))), 5.1-5.9 (NH), 6.7-8.7 (Ph (NQ). ${ }^{13} \mathrm{C}-\mathrm{NMR}$ (400 MHz, solid-state, $\left.\delta \mathrm{ppm}\right): 24-58\left(\mathrm{br}, \mathrm{CH}_{2}\right)$, 96-112 (br, $\left.-\mathrm{CH}_{2}-\mathrm{N}\right), 114-142(\mathrm{br},=\mathrm{C}-\mathrm{N}), 142-156(\mathrm{br},-$ $\mathrm{C}=), 168-192(\mathrm{br}, \mathrm{C}=\mathrm{O})$. The degree of substitution of NQ in poly(allylamine) was determined by the same method to be $26 \%$ (143 $\mathrm{mAh} / \mathrm{g}$ as a theoretical capacity).

In short, the trimeric precursor (EPE), terthiophene $\mathrm{EP}(\mathrm{OH}) \mathrm{E}$ $(\mathrm{OH}=$ hydroxyl $)$, was prepared following the synthetic route developed by Thayumanavan and co-workers. ${ }^{32}$

EP(NQ)E was synthesized, as previously reported; shortly, $\mathrm{EP}(\mathrm{OH}) \mathrm{E}$ was used, and subsequently, a carboxylic acid-function- alized NQ derivate was attached using EDC- $\mathrm{HCl}$ coupling conditions, resulting in $\mathrm{EP}(\mathrm{NQ}) \mathrm{E}$.

2.3. Electrode Manufacturing. In all electrode compositions, a glassy carbon (GC) (HTW, Germany) substrate with dimensions of $40 \mathrm{~mm} \times 8 \mathrm{~mm} \times 2 \mathrm{~mm}$ acted as the current collector. About $1 \mathrm{mg}$ of the electrode material was deposited on about $\sim 0.5 \mathrm{~cm}^{2}$, and consequently, mass loading was in general $\sim 2 \mathrm{mg} / \mathrm{cm}^{2}$ for all experiments.

2.3.1. $p E P(N Q) E$. $\mathrm{EP}(\mathrm{NQ}) \mathrm{E}(10 \mathrm{mg})$ was dissolved in $100 \mu \mathrm{L}$ of NMP. Ten microliters, i.e., $1 \mathrm{mg}$ of the material, was drop-casted on the GC electrode, which subsequently was dried in vacuum for $1 \mathrm{~h}$. Polymerization of the deposited EP(NQ)E layer, the so-called postdeposition polymerization, was then achieved by applying a potential of $0.81 \mathrm{~V}$ versus standard hydrogen electrode (SHE) in an aqueous solution (1 M p-toluenesulfonic acid (aq)) until the residual current was below $0.1 \mathrm{~mA}$.

2.3.2.PNQ@pEPE. Solution 1: $10 \mathrm{mg}$ of the trimer was dissolved in $100 \mu \mathrm{L}$ of NMP resulting in a solution containing $208 \mathrm{mM}$ EPE. Solution 2: Similarly, $10 \mathrm{mg}$ of PNQ was also dissolved in $100 \mu \mathrm{L}$ of NMP. Using a pipette, solution 1 and solution 2 were mixed in varying amounts resulting in different ratios between EPE and PNQ but always equaling to $10 \mu \mathrm{L}$ in total, i.e., $1 \mathrm{mg}$ of the total electrode material. The solution was subsequently drop-casted on the current collector, which was then dried in vacuum for $1 \mathrm{~h}$. Polymerization of the deposited PNQ@EPE layer, the so-called post-deposition polymerization, was then achieved by applying a potential of $0.81 \mathrm{~V}$ versus SHE in an aqueous solution (1 M p-toluenesulfonic acid (aq)) until the residual current was below $0.1 \mathrm{~mA}$.

2.3.3. Comparison with Carbon as Conducting Additive. In the study, the carbon additives studied were carbon blacks BP2000 and PBX51 (both used as received from Cabot Corp.) and SWCNT (received from Meijo Nano Carbon Corp.). PNQ was dissolved in NMP and was subsequently thoroughly grinded together with the carbon additive and polyvinylidene fluoride (PVDF) as the binder in a ratio of 0.4:0.5:0.1 (PNQ:conducting additive:PVDF). The resulting slurry was coated on a GC electrode and dried in vacuum.

2.4. Electrochemical Measurements. Three electrode results were obtained using an Autolab PGSTAT302N potentiostat (Ecochemie, Utrecht, The Netherlands). The drop-casted electrodes were put into a beaker cell filled with $0.5 \mathrm{M} \mathrm{H}_{2} \mathrm{SO}_{4}$ (aq) as the electrolyte. The electrolyte was degassed with $\mathrm{N}_{2}$ and remained under an inert atmosphere during the whole experiment. $\mathrm{An} \mathrm{Ag} / \mathrm{AgCl}$ (3 M $\mathrm{NaCl}, 0.209 \mathrm{~V}$ vs SHE) electrode was used as reference, and a platinum wire served as the counter electrode. For battery cycling, a Biologic BCS-810 instrument was used. For in situ conductance measurements, $1 \mathrm{mg}$ of the active material was coated onto an IDA electrode with 90 pairs of $\mathrm{Au}$ bands on a glass substrate $(10 \mathrm{~mm}$ between bands, $150 \mathrm{~nm}$ high, MicruX Technologies, Spain). A potential bias of $10 \mathrm{mV}$ was applied, and conductance was calculated, as previously reported. ${ }^{33}$ The scan rate was $10 \mathrm{mV} / \mathrm{s}$. For the twoelectrode battery experiments, a GC electrode with the $\mathrm{CP} / \mathrm{RP}$ composites was used as an anode together with a carbon felt (AvCarb) with $\mathrm{MnSO}_{4}$ deposited as a cathode. The cathode material was deposited by applying a potential of $1.2 \mathrm{~V}$ versus $\mathrm{Ag} / \mathrm{AgCl}$ for 100 $\mathrm{s}$ in a $0.05 \mathrm{M} \mathrm{H}_{2} \mathrm{SO}_{4} / 1 \mathrm{M} \mathrm{MnSO}_{4}$ (aq) electrolyte. Both the anode and cathode were put in a beaker cell with the $\mathrm{H}_{2} \mathrm{SO}_{4} / 1 \mathrm{M} \mathrm{MnSO}_{4}$ (aq) electrolyte, which was degassed with $\mathrm{N}_{2}$ and remained under an inert atmosphere during the whole experiment.

2.5. Scanning Electron Microscopy (SEM). SEM was carried out using a Leo Gemini 1550 FEG SEM instrument (Zeiss, Germany) equipped with both an in-lens and energy-dispersive X-ray (EDX) detector. No sputtering was necessary since the conducting properties of the polymer were sufficient.

\section{RESULTS AND DISCUSSION}

3.1. Preparation of CP/RP Composite Using PostDeposition Polymerization. While there are many available CPs, we chose a trimeric precursor consisting of 3,4ethylenedioxythiophene (E) and 3,4-propylenedioxythiophene 
(P), which are well-known to result in CPs with good conductivity and high chemical stability. ${ }^{34,35}$ These polymers also exhibited a low doping onset potential (Figure S3), the importance of which we will discuss further. To apply the method of post-deposition polymerization, we designed a soluble trimeric CP precursor, EPE (Figure 1). EPE can easily

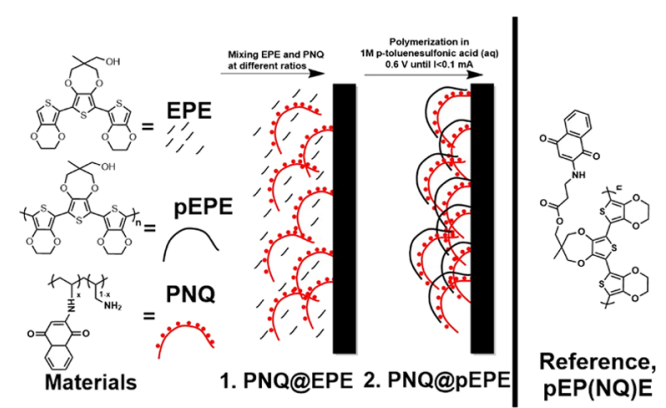

Figure 1. Schematic showing the process for creating CP/RP composites. The materials are composed of a CP precursor, EPE, which polymerizes to $\mathrm{pEPE}$ and PNQ. EPE and NQ are mixed and dried, resulting in a PNQ@EPE composite; subsequently, an oxidative potential $(0.8 \mathrm{~V}$ vs $\mathrm{SHE})$ is applied in a $1 \mathrm{M} p$-toluenesulfonic acid (aq) solution until the residual current is below $0.1 \mathrm{~mA}$, which creates $\mathrm{CP} / \mathrm{RP}$ composite PNQ@pEPE. Also, the structure of the reference material, $\mathrm{pEP}(\mathrm{NQ}) \mathrm{E}$, is shown on the left.

be blended with the RP in solution. It is important to mention that the propylenedioxythiophene unit in the trimeric precursor is substituted with a hydroxyl $(\mathrm{OH})$ group, which enhances solubility in common organic solvents. (For simplicity, we refer to the trimer in the subsequent text as EPE instead of $\operatorname{EP}(\mathrm{OH}) \mathrm{E})$. RP bearing NQ was prepared via the nucleophilic substitution of poly(allylamine) and 2-bromo1,4-naphthoquinone, which proceeds in ambient conditions and the hydrophilicity of the RP can easily be tuned by changing the NQ introduction rate to poly(allylamine).

The EPE trimer was dissolved together with PNQ and the blend was coated onto a current collector and dried. Subsequently, the EPE portion of the blend was polymerized electrochemically by applying an oxidative potential $(0.8 \mathrm{~V}$ vs SHE) to yield a CP (pEPE), resulting in a blend of CPs and RPs, i.e., PNQ@pEPE (Figure 1). Polymerization was complete in less than $100 \mathrm{~s}$ (Figure S4), with higher currents and longer durations for blends with a higher content of the $\mathrm{CP}$, which is plausible since the current response during polymerization stems from the conversion of EPE to pEPE. The water-insoluble trimer was polymerized in an aqueous solution of $1 \mathrm{M}$ p-toluenesulfonic acid (PTSA), which gave superior results compared to using $0.5 \mathrm{M} \mathrm{H}_{2} \mathrm{SO}_{4}$, i.e., more capacity achieved (Figure S5). As will be discussed further in the evaluation of the electrode materials, this might indicate that wetting of slightly hydrophobic PNQ is improved by the PTSA anions, which are introduced in the structure as a result of polymerization.

When evaluating the $\mathrm{CP} / \mathrm{RP}$ composites for battery applications, ultimately, the specific capacity per total electrode weight and rate capabilities have to be considered. Ideally, a low amount of the CP additive should enable all capacities of the RP to be accessed. Importantly though, the CP is only conducting in certain potential regions, i.e., above a doping onset potential, as opposed to carbon conducting additives that supply conductivity independent of the applied potential.
Furthermore, the conducting properties of the CP might be affected by the presence of the RP in the composite. Before studying electrode characteristics such as specific capacity, we ensured favorable conducting properties and measured the conductivity as a function of potential using different ratios of the CP to RP, ranging from 10 to 100 wt \% pEPE (Figure 2). All data have been compiled in Table 1 below, which we will refer to throughout the text.

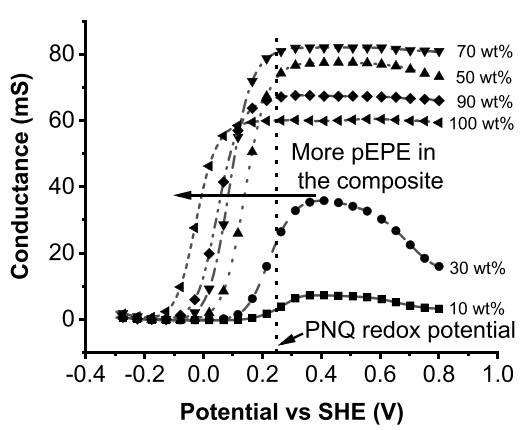

Figure 2. In situ conductance for PNQ@pEPE at different CP/RP ratios (10-100 wt \% pEPE) in the PNQ@pEPE blend, as evaluated using bipotentiostat measurements on PNQ@pEPE-covered interdigitated array electrodes. A potential bias of $10 \mathrm{mV}$ between the two working electrodes was applied, and the potential was varied cyclically at a scan rate of $10 \mathrm{mV} / \mathrm{s}$.

Interestingly, with an increase in the pEPE content in the electrode composition, the doping onset potential is slightly downshifted from 0.2 (10 wt \% pEPE) to $-0.1 \mathrm{~V}$ (100 wt \% $\mathrm{pEPE}$ ) versus SHE. This phenomenon should be attributed to different chain lengths in the polymers with different CP/RP ratios, where shorter polymer chains result in higher doping onset potentials. ${ }^{36-38}$ This is plausible since a higher percentage of the RP could result in a disruption of chain growth. Two regimes in conductance can be observed, a regime with high conductivity with slight variations in the cases of 50-100 wt \% pEPE and a regime with lower conductivity for 10 and $30 \mathrm{wt} \% \mathrm{pEPE}$. In the lower regime, a peak at around $0.4 \mathrm{~V}$ versus SHE can also be seen, which indicates electron hopping, further strengthening the notion that shorter polymer chains are formed in these composites. It is important to note that the difference in conductance might have an effect on the rate capabilities, which will be discussed later, where low conductance in the material could be rate-limiting at high C-rates. Importantly, in all cases, the potential of the NQ redox conversion, $0.26 \mathrm{~V}$ versus $\mathrm{SHE}$, is above the conductance onset potential for the $\mathrm{CP}$, implicating that the $\mathrm{CP}$ will supply conductivity for the RP in all $\mathrm{CP} / \mathrm{RP}$ composites. We therefore conclude that $\mathrm{pEPE}$ should, in theory, be a suitable candidate as a conducting additive for a NQ-based RP.

To ensure that blending in the $\mathrm{CP} / \mathrm{RP}$ composite is optimal, i.e., no distinct separate phases of the $\mathrm{CP}$ or RP exist, we studied the composites visually with SEM (Figure S6). Clearly, in all cases, a uniform film, about $10 \mu \mathrm{m}$ thick, is achieved with little variance between the different $\mathrm{CP} / \mathrm{RP}$ compositions. EDX elemental mapping was used to further explore this notion (Figures S7-S11). Since PNQ contains nitrogen, whereas $\mathrm{pEPE}$ contains sulfur, separate phases would be easily identified. All compositions exhibit an even distribution between nitrogen and sulfur in the material, indicating a uniform distribution of PNQ and pEPE in the material, which is crucial for efficient charge transport. 
Table 1. Compiled Data for CP/RP Composites from $10(1: 9)$ to 100 wt $\%$ pEPE (10:0) ${ }^{a}$

\begin{tabular}{|c|c|c|c|c|c|}
\hline $\begin{array}{l}\text { composite } \\
\text { composition }\end{array}$ & $\begin{array}{c}\text { onset } \\
\text { potential }(\mathrm{V})\end{array}$ & $\begin{array}{c}\text { maximum } \\
\text { conductance }(\mathrm{mS})\end{array}$ & $\begin{array}{l}\text { specific capacity at } 1 \mathrm{C} \\
(\mathrm{mAh} / \mathrm{g})\end{array}$ & $\begin{array}{l}\text { capacity contributed by the } \\
\text { CP }(\mathrm{mAh} / \mathrm{g})\end{array}$ & $\begin{array}{l}\text { specific capacity expected from PNQ } \\
(\mathrm{mAh} / \mathrm{g}), \% \text { accessed }\end{array}$ \\
\hline $1: 9$ & 0.26 & 7 & 54 & 2 & 129,40 \\
\hline $3: 7$ & 0.22 & 35 & 77 & 7 & 100,70 \\
\hline $5: 5$ & 0.14 & 77 & 64 & 12 & 72,72 \\
\hline $7: 3$ & 0.09 & 82 & 49 & 16 & 43,76 \\
\hline $9: 1$ & 0.05 & 68 & 31 & 20 & 14,64 \\
\hline $10: 0$ & -0.02 & 60 & 23 & 23 & 0 \\
\hline
\end{tabular}

${ }^{a}$ In all composites, the total amount of the material on the electrode was maintained at $1 \mathrm{mg}$. The table shows doping onset potentials, maximum capacitances achieved, specific capacities at $1 \mathrm{C}$, the capacities contributed by the $\mathrm{CP}$, and the specific capacities that would be expected from PNQ if all materials would be accessed. Furthermore, the percentage of the accessed material is reported.

3.2. Evaluation of the PNQ@pEPE Electrode. Having established the potential of $\mathrm{pEPE}$ as a conducting additive for a NQ-based RP, we moved on to evaluate the electrochemical performance of PNQ@pEPE. Similar to the conductance measurements, we chose different ratios of the CP/RP to evaluate how much of the RP capacity (theoretical, $143 \mathrm{mAh} /$ g) could be reached as well as the rate capability for each composition. Furthermore, we compared the results with the previously reported performance of the conducting $\mathrm{RP}$, $\mathrm{pEP}(\mathrm{NQ}) \mathrm{E}$ (Figure 3). Since the specific capacity for the

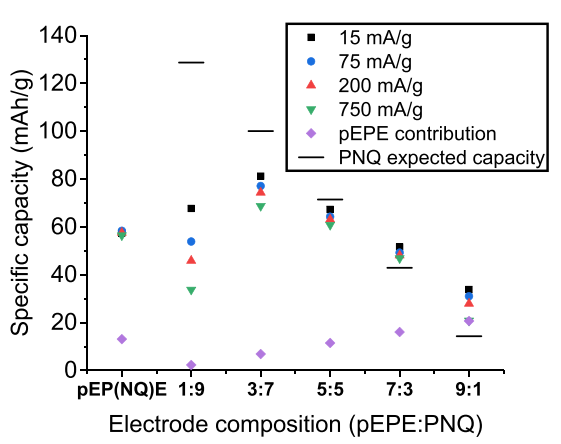

Figure 3. Specific capacity of materials with different ratios of $\mathrm{pEPE}$ $(10-90 \mathrm{wt} \%)$ and PNQ $(90-10 \mathrm{wt} \%)$ in the electrode composition and $\mathrm{pEP}(\mathrm{NQ}) \mathrm{E}$. Their specific capacity is calculated for the total electrode weight and given for different charging currents ranging from $15(0.2 \mathrm{C})$ to $750 \mathrm{~mA} / \mathrm{g}(10 \mathrm{C})$. Also, the capacity that would be expected to result from the pEPE additive is given (diamond) together with the capacity that would result if the entire theoretical specific capacity of PNQ would be accessed (black line).

electrode, including the conducting additive, has to be optimized for the use in a battery application, we evaluate and report capacities calculated for the entire electrode weight, including both the RP and CP. The capacities are extracted from the second scan of the galvanostatic charge-discharge experiments starting from pristine electrodes. For $\mathrm{pEP}(\mathrm{NQ}) \mathrm{E}$, the capacities, at all current rates, are around $58 \mathrm{mAh} / \mathrm{g}$, where $13 \mathrm{mAh} / \mathrm{g}$, as measured from an experiment with $100 \% \mathrm{pEPE}$, can be attributed to the capacity from the conducting backbone. This is similar to the capacities achieved by compositions 1:9, 5:5, and 7:3 pEPE:PNQ that resulted in 53,63 , and $48 \mathrm{mAh} / \mathrm{g}$, respectively, using a charging current of $75 \mathrm{~mA} / \mathrm{g}$. Clearly, the highest overall capacity is achieved with a composition of $3: 7$ with a capacity of $77 \mathrm{mAh} / \mathrm{g}$. Importantly, even in this case, the capacity of the electrode is far from what would be expected based on the theoretical capacities. Since the electrode contains 70 wt \% PNQ one would expect a $100 \mathrm{mAh} / \mathrm{g}$ capacity contribution from the RP
(Figure 3, black line; $100 \mathrm{mAh} / \mathrm{g}$ at $70 \%$ total weight), but when accounting for the capacity contribution of the CP (in this case $7 \mathrm{mAh} / \mathrm{g}$ ), only $70 \%$ of the theoretical capacity can be achieved. This fact could be attributed to the $\pi-\pi$ interaction of the NQ group in the polymer or insufficient hydrophilicity, rendering parts of the polymer inactive (vide infra). When evaluating the rate capabilities, an interesting trend can be observed, where increasing the pEPE content in the composite leads to a narrower split between capacities from low rates and capacities from high rates. This indicates that pEPE improves rate capabilities, which can both be attributed to better ion and electron transport. We further evaluated the current response by oxidizing the material from the reduced state through a potential step from 0 to $0.4 \mathrm{~V}$ versus SHE (Figure S12). Clearly, redox conversion is fast in all cases, which is reflected by the initially high currents exhibited and only small residual currents presented after $20 \mathrm{~s}$. By investigating the Cottrell behavior (Figure S12, inset), diffusion coefficients for all composites were determined, assuming $10 \mu \mathrm{m}$ film thicknesses in all cases. The diffusion coefficients ranged from $1.1 \times 10^{-11}$ $\mathrm{cm}^{2} / \mathrm{s}$ in the case of composite $1: 9$ to $1.5 \times 10^{-9} \mathrm{~cm}^{2} / \mathrm{s}$ in the case of composite 7:3 (Table S1), which are in accordance with previously reported diffusion coefficients for $\mathrm{RPs}^{39}$ and CPs. ${ }^{40}$ This underscores the relevance of $\mathrm{pEPE}$ as a conducting additive for organic batteries.

To put the results from using $\mathrm{pEPE}$ as a conducting additive into perspective, we chose three different conducting carbons as references. While most inorganic and organic batteries use conductive carbons, few systematic studies exist on this topic, especially for water-based electrolytes. We therefore utilize single-walled carbon nanotubes (SWCNT), reported as a conductive additive in numerous studies, ${ }^{5,31,41}$ together with two carbon blacks (CBs) with a similar surface area. One is hydrophobic (BP2000), and one is hydrophilic (PBX51). PBX51 is employed in, for example, lead-acid batteries due to its hydrophilic character. Using a ratio of a $50 \mathrm{wt} \%$ carbon additive and $40 \mathrm{wt} \%$ PNQ together with a 10\% PVDF binder, capacities of $25 \mathrm{mAh} / \mathrm{g}$ for BP2000, $39 \mathrm{mAh} / \mathrm{g}$ for SWCNT, and $45 \mathrm{mAh} / \mathrm{g}$ for PBX51 could be achieved (Figure S13), which are far from the theoretical capacity of PNQ and lower than the values obtained by using $\mathrm{pEPE}$ (vide supra). Although the processing of electrodes with the carbon materials likely could be optimized further, we interpret the achieved capacities using carbon additives as a further indication that PNQ is hard to access by the aqueous electrolyte. With almost twice the capacity achieved by PBX51 over the hydrophobic analogue BP2000, choosing a suitable carbon additive is clearly important. However, by using EPE as a soluble alternative, more materials can be immediately accessed circumventing the 

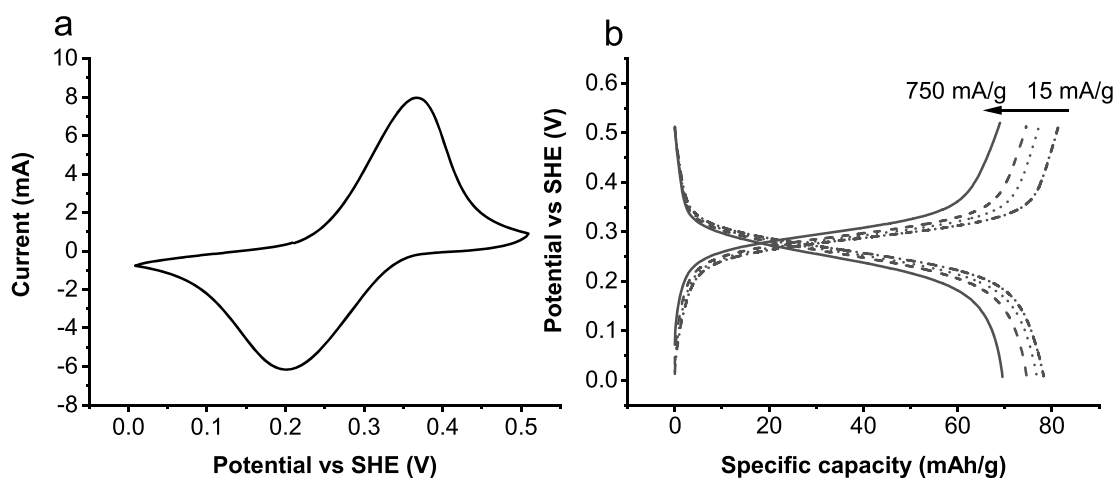

Figure 4. Electrochemical characteristics of 3:7 PNQ@pEPE; cyclic voltammogram of the redox response (a) at a scan rate of $5 \mathrm{mV} / \mathrm{s}$ and potential profile (b) at different charging currents ranging from $15(0.2 \mathrm{C})$ to $750 \mathrm{~mA} / \mathrm{g}(10 \mathrm{C})$.
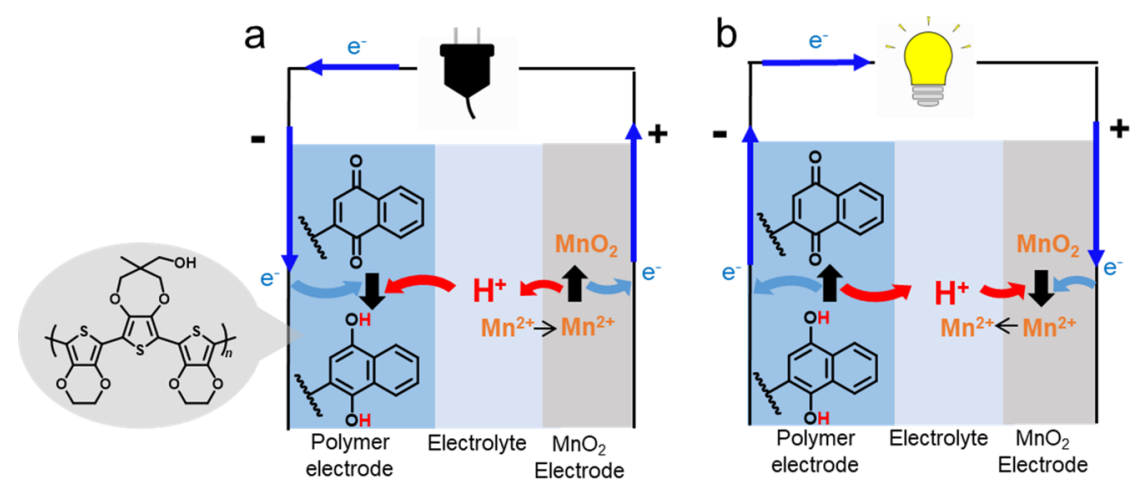

Figure 5. Electrochemical properties of the polymer-manganese secondary battery. Schematic image of the battery (a) charging and (b) discharging.

dispersion process when using insoluble carbon conducting additives. The function of $\mathrm{pEPE}$ in aqueous electrolytes also compares favorably to hydrophilic CB designed for lead-acid batteries.

To show that $\mathrm{pEPE}$ promotes high ion and electron transport rates when used as a combined conducting and binder additive, we also investigated $\mathrm{pEPE}$ composited with an anthraquinone-based RP, poly(vinylanthraquinone) (PVAQ). PVAQ is similar in structure to PNQ and could only be used under alkaline conditions due to wettability issues. Even at $\mathrm{pH}$ 8 , the lowest $\mathrm{pH}$ studied, only $10 \%$ of the theoretical capacity of PVAQ could be accessed even in very thin layers (around $100 \mathrm{~nm}$ thick). Increasing the $\mathrm{pH}$ allowed more polymer swelling since non-protonated anthraquinone in its reduced form $\left(\mathrm{AQ}^{2-}\right)$ becomes more predominant, which improves electrolyte wetting. ${ }^{42}$ It can therefore be speculated that $\mathrm{pEPE}$ might actually improve performance since the dopant ion (the anion of $p$-toluenesulfonic acid) likely introduces water into the composite structure, increasing wettability of PNQ which would explain why PNQ@pEPE outperforms the carbon-based electrode compositions. We further explored this notion by using PVAQ in a composite CP/RP electrode with $80 \% \mathrm{pEPE}$ and 20\% PVAQ. It can be noted that a clear redox response at $\mathrm{pH}$ around 1 is present (Figure S14a). When taking into account the plateau from the PVAQ redox conversion, a capacity of around $70 \mathrm{mAh} / \mathrm{g}$ is achieved, which is $30 \%$ of the theoretical capacity (Figure S14b). While this is still low, the mere fact that using $\mathrm{pEPE}$ as a conducting additive enables cycling of an AQ polymer under acid conditions, showing that $\mathrm{pEPE}$ indeed has a positive effect on wettability.
We further investigated this notion by comparing the contact angle of a drop of water on either PNQ or PNQ@ pEPE (Figure S15). It can be clearly seen that the contact angle is larger in the PNQ case, as compared to PNQ@pEPE, confirming improved wettability resulting from the addition of pEPE.

When moving forward to use any of the evaluated polymer composite electrodes in a full battery cell, two main aspects are of interest. First, the capacity of the composite, which includes contribution from both $\mathrm{pEPE}$ and $\mathrm{PNQ}$, should be as high as possible. Here, composite 3:7 with $77 \mathrm{mAh} / \mathrm{g}$ is the most promising candidate. Second, rate capabilities have to be favorable. Here, a slight positive trend with increasing the pEPE content is observed (except for the extreme case of $90 \%$ pEPE). However, all composites exhibit good rate capabilities, clearly showing the favorable rate capabilities that can be achieved using quinone redox groups, as previously reported. $^{42,43}$ The low conductance regime affecting composites 1:9 and 3:7, as shown in Figure 2, does not have the negative effect we speculated on when it comes to rate capability, indicating that conductivity supplied by the CP is sufficient in all cases. In the case of composite 3:7, looking at the corresponding cyclic voltammogram, a clear redox peak can be seen upon oxidation and reduction with an $E_{1 / 2}$ of 0.26 $\mathrm{V}$ versus SHE (Figure 4a), which is, as mentioned earlier, above the conductance onset potential for $\mathrm{pEPE}$. At different charging currents from $15(0.2 \mathrm{C})$ to $750 \mathrm{~mA} / \mathrm{g}(10 \mathrm{C})$, the discharge capacity only varied slightly from 81 to $69 \mathrm{mAh} / \mathrm{g}$, respectively (Figure 4b), which indicated good rate capability of the composite electrode. Since both the composite capacities were the highest of all composites studied and rate 

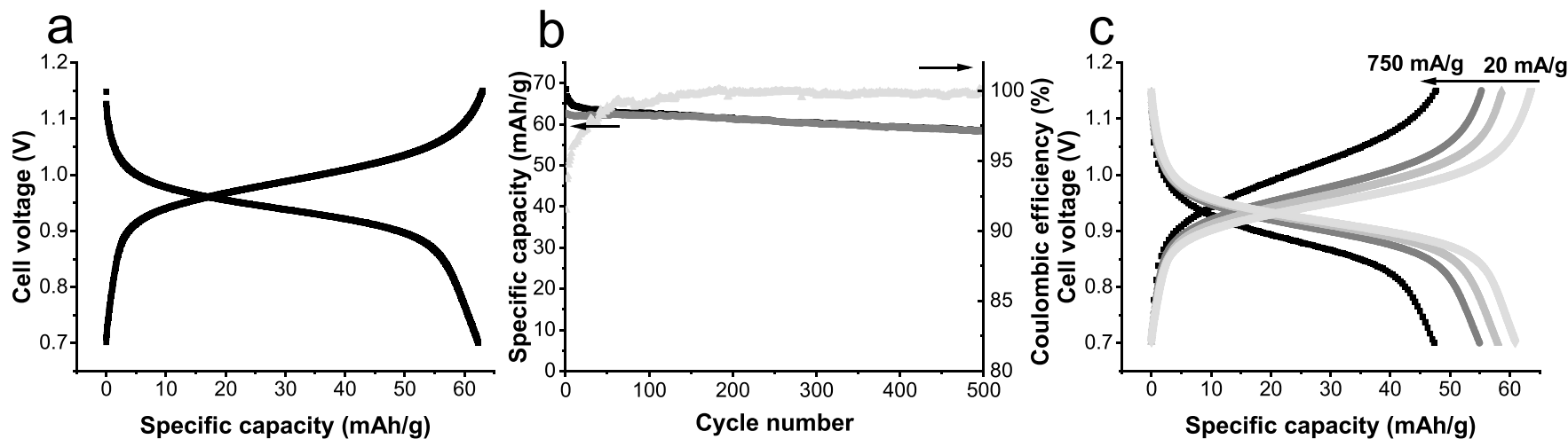

Figure 6. Battery characteristics: voltage profile (a), cycling stability during 500 cycles at $1 \mathrm{C}$ (b) for charge (black) and discharge (gray) with corresponding Coulombic efficiency (light gray), and voltage profiles at different rates from 20 (corresponding to 0.3 ) to $750 \mathrm{~mA} / \mathrm{g}$ (corresponding to $10 \mathrm{C}$ ) for 3:7 PNQ@pEPE (c).

capabilities were favorable, we continued further with this electrode composition for evaluation in a battery setting.

3.3. Battery Evaluation. To explore the full potential of PNQ@pEPE in a battery setting, we used it as an anode material together with an inorganic cathode $\left(\mathrm{Mn}^{2+} / \mathrm{MnO}_{2}\right)$. By selecting a stable, well-established cathode with known characteristics, i.e., rate capabilities and cycling stability, it is possible to ensure that the observed responses can be attributed to the PNQ@pEPE anode. ${ }^{44}$ We chose a large excess of the cathode material to the extent that the highest rates studied in our battery experienced by the cathode $(0.75$ $\mathrm{mA} / \mathrm{cm}^{2}$ ) were below the rates that have been previously established $\left(200 \mathrm{~mA} / \mathrm{cm}^{2}\right)$ for the that material, thus ensuring that the cathode reaction will not be rate-limiting. As a matter of fact, when monitoring both the anode and cathode during battery cycling versus an external $\mathrm{Ag} / \mathrm{AgCl}$ electrode, no change in the cathode potential was observed, and the potential profile of the battery could be entirely attributed to the anode (Figure S16). It is important to mention though that, in this battery design, no complete rocking chair motion of the ions, which is one of the major advantages with allquinone-based batteries, is achieved, but instead, different ions $\left(\mathrm{H}^{+}\right.$and $\left.\mathrm{Mn}^{2+}\right)$ take part in the respective redox reactions (anode: $\mathrm{NQ}+2 \mathrm{H}^{+}+2 \mathrm{e}^{-} \rightarrow \mathrm{NQH}_{2}$; cathode: $\mathrm{MnO}_{2}+4 \mathrm{H}^{+}+2$ $\mathrm{e}^{-} \rightarrow \mathrm{Mn}^{2+}+2 \mathrm{H}_{2} \mathrm{O}$; Figure 5).

When evaluating the battery using a current of $75 \mathrm{~mA} / \mathrm{g}$, roughly corresponding to $1 \mathrm{C}$, a discharge plateau at $0.95 \mathrm{~V}$ with a discharge capacity of $63 \mathrm{mAh} / \mathrm{g}$ (Figure 6a) was observed. Cycling this way at $1 \mathrm{C}$ for 500 cycles, the battery retains $93 \%$ of its initial capacity at a Coulombic efficiency of around $100 \%$ (Figure $6 \mathrm{~b}$ ). Evaluating the rate capabilities, similar results as in the three-electrode setup are observed with capacities of $48 \mathrm{mAh} / \mathrm{g}$ for $750 \mathrm{~mA} / \mathrm{g}, 55 \mathrm{mAh} / \mathrm{g}$ for $200 \mathrm{~mA} /$ g, $58 \mathrm{mAh} / \mathrm{g}$ for $75 \mathrm{~mA} / \mathrm{g}$, and $63 \mathrm{mAh} / \mathrm{g}$ for $20 \mathrm{~mA} / \mathrm{g}$ (Figure $6 c)$. Clearly, the rate capabilities are almost identical to what has been achieved in the three-electrode evaluation of PNQ@ $\mathrm{pEPE}$, suggesting that the performance is indeed related to the anode.

\section{CONCLUSIONS}

Here, we present how a CP, formed from a soluble precursor, can be used as a combined conducting and binder material in organic electrodes. We show that PNQ is suitable in this setting since its redox potential is above the onset potential of the conducting additive. In this case, a maximum capacity (77
$\mathrm{mAh} / \mathrm{g})$, based on the total electrode weight, was achieved when using 30 wt \% pEPE and 70 wt \% PNQ. Furthermore, pEPE improved the capacity achieved compared to carbon black as an additive, which is attributed to the hydrophobic nature of PNQ. PNQ@pEPE shows good rate capability. A battery, with a $\mathrm{MnO}_{2}$ cathode and PNQ@pEPE as the anode, exhibited a voltage of $0.95 \mathrm{~V}$ and high cyclability $(>500$ cycles). In a future work, pEPE could be explored as conductive additives in other types of organic redox-active materials as well as in inorganic materials.

\section{ASSOCIATED CONTENT}

SI Supporting Information

The Supporting Information is available free of charge at https://pubs.acs.org/doi/10.1021/acsami.0c22578.

Electrochemical data, ${ }^{1} \mathrm{H}-\mathrm{NMR}$ spectrum, ${ }^{13} \mathrm{C}-\mathrm{NMR}$ spectrum, and SEM-EDX images (PDF)

\section{AUTHOR INFORMATION}

\section{Corresponding Authors}

Rikard Emanuelsson - Nanotechnology and Functional Materials, Department of Materials Science and Engineering, The Ångström Laboratory, Uppsala University, SE-751 03 Uppsala, Sweden; 이잉.org/0000-0002-4726-4121; Email: Martin.Sjodin@angstrom.uu.se

Martin Sjödin - Nanotechnology and Functional Materials, Department of Materials Science and Engineering, The Ångström Laboratory, Uppsala University, SE-751 03 Uppsala, Sweden; O orcid.org/0000-0003-4126-4347; Email: Rikard.Emanuelsson@angstrom.uu.se

\section{Authors}

Christian Strietzel - Nanotechnology and Functional Materials, Department of Materials Science and Engineering, The Angström Laboratory, Uppsala University, SE-751 03 Uppsala, Sweden

Kouki Oka - Nanotechnology and Functional Materials, Department of Materials Science and Engineering, The Ångström Laboratory, Uppsala University, SE-751 03 Uppsala, Sweden; (1) orcid.org/0000-0001-6806-2767

Maria Strømme - Nanotechnology and Functional Materials, Department of Materials Science and Engineering, The Ångström Laboratory, Uppsala University, SE-751 03 Uppsala, Sweden; orcid.org/0000-0002-5496-9664

Complete contact information is available at: 
https://pubs.acs.org/10.1021/acsami.0c22578

\section{Author Contributions}

${ }^{\dagger}$ C.S. and K.O. contributed equally to this work.

\section{Funding}

This work was funded by the Swedish Energy Agency, the Carl Trygger Foundation, and the Research Council Formas. R.E. acknowledges the Åforsk foundation for a personal grant (17344).

Notes

The authors declare no competing financial interest.

\section{ACKNOWLEDGMENTS}

We thank Nittobo Medical Co., Ltd. for providing poly(allylamine) and Cabot Corp. for providing the carbon blacks.

\section{REFERENCES}

(1) Armand, M.; Tarascon, J. M. Building Better Batteries. Nature 2008, 451, 652-657.

(2) Poizot, P.; Dolhem, F.; Gaubicher, J. Progress in All-Organic Rechargeable Batteries Using Cationic and Anionic Configurations: Toward Low-Cost and Greener Storage Solutions? Curr. Opin. Electrochem. 2018, 9, 70-80.

(3) Poizot, P.; Dolhem, F. Clean Energy New Deal for a Sustainable World: From Non-Co2 Generating Energy Sources to Greener Electrochemical Storage Devices. Energy Environ. Sci. 2011, 4, 20032019.

(4) Casado, N.; Hernández, G.; Sardon, H.; Mecerreyes, D. Current Trends in Redox Polymers for Energy and Medicine. Prog. Polym. Sci. 2016, 52, 107-135.

(5) Oka, K.; Kato, R.; Oyaizu, K.; Nishide, H. Poly(Vinyldibenzothiophenesulfone): Its Redox Capability at Very Negative Potential toward an All-Organic Rechargeable Device with High-Energy Density. Adv. Funct. Mater. 2018, 28, 1805858.

(6) Nishide, H.; Iwasa, S.; Pu, Y.-J.; Suga, T.; Nakahara, K.; Satoh, M. Organic Radical Battery: Nitroxide Polymers as a Cathode-Active Material. Electrochim. Acta 2004, 50, 827-831.

(7) Oyaizu, K.; Nishide, H. Redox-Active Polymers as an Organic Energy Storage Material. In Conjugated Polymers; CRC Press: 2019; pp. 587-594, DOI: 10.1201/9780429190520-19.

(8) Nishide, H.; Oyaizu, K. Materials Science. Toward Flexible Batteries. Science 2008, 319, 737-738.

(9) Chen, H.; Armand, M.; Courty, M.; Jiang, M.; Grey, C. P.; Dolhem, F.; Tarascon, J.-M.; Poizot, P. Lithium Salt of Tetrahydroxybenzoquinone: Toward the Development of a Sustainable Li-Ion Battery. J. Am. Chem. Soc. 2009, 131, 8984-8988.

(10) Perticarari, S.; Sayed-Ahmad-Baraza, Y.; Ewels, C.; Moreau, P.; Guyomard, D.; Poizot, P.; Odobel, F.; Gaubicher, J. Dual AnionCation Reversible Insertion in a Bipyridinium-Diamide Triad as the Negative Electrode for Aqueous Batteries. Adv. Energy Mater. 2018, 8, 1701988.

(11) Perticarari, S.; Grange, E.; Doizy, T.; Pellegrin, Y.; Quarez, E.; Oyaizu, K.; Fernandez-Ropero, A. J.; Guyomard, D.; Poizot, P.; Odobel, F.; Gaubicher, J. Full Organic Aqueous Battery Based on Tempo Small Molecule with Millimeter-Thick Electrodes. Chem. Mater. 2019, 31, 1869-1880.

(12) Tong, L.; Jing, Y.; Gordon, R. G.; Aziz, M. J. Symmetric AllQuinone Aqueous Battery. ACS Appl. Energy Mater. 2019, 2, 40164021.

(13) Liang, Y.; Jing, Y.; Gheytani, S.; Lee, K.-Y.; Liu, P.; Facchetti, A.; Yao, Y. Universal Quinone Electrodes for Long Cycle Life Aqueous Rechargeable Batteries. Nat. Mater. 2017, 16, 841-848.

(14) Maniam, S.; Oka, K.; Nishide, H. N-Phenyl Naphthalene Diimide Pendant Polymer as a Charge Storage Material with High Rate Capability and Cyclability. MRS Commun. 2017, 7, 967-973.

(15) Kato, R.; Oka, K.; Yoshimasa, K.; Nakajima, M.; Nishide, H.; Oyaizu, K. Reversible Hydrogen Releasing and Fixing with Poly-
(Vinylfluorenol) through a Mild Ir-Catalyzed Dehydrogenation and Electrochemical Hydrogenation. Macromol. Rapid Commun. 2019, No. e1900139.

(16) Muench, S.; Wild, A.; Friebe, C.; Häupler, B.; Janoschka, T.; Schubert, U. S. Polymer-Based Organic Batteries. Chem. Rev. 2016, 116, 9438-9484.

(17) Oka, K.; Furukawa, S.; Murao, S.; Oka, T.; Nishide, H.; Oyaizu, K. Poly(Dihydroxybenzoquinone): Its High-Density and Robust Charge Storage Capability in Rechargeable Acidic Polymer-Air Batteries. Chem. Commun. 2020, 56, 4055-4058.

(18) Emanuelsson, R.; Sterby, M.; Strømme, M.; Sjödin, M. An AllOrganic Proton Battery. J. Am. Chem. Soc. 2017, 139, 4828-4834.

(19) Karlsson, C.; Strietzel, C.; Huang, H.; Sjödin, M.; Jannasch, P. Nonstoichiometric Triazolium Protic Ionic Liquids for All-Organic Batteries. ACS Applied Energy Materials 2018, 1, 6451-6462.

(20) Oka, K.; Strietzel, C.; Emanuelsson, R.; Nishide, H.; Oyaizu, K.; Stromme, M.; Sjodin, M. Conducting Redox Polymer as a Robust Organic Electrode-Active Material in Acidic Aqueous Electrolyte Towards Polymer-Air Secondary Batteries. ChemSusChem 2020, 13, $2280-2285$.

(21) Oka, K.; Löfgren, R.; Emanuelsson, R.; Nishide, H.; Oyaizu, K.; Strømme, M.; Sjödin, M. Conducting Redox Polymer as Organic Anode Material for Polymer-Manganese Secondary Batteries. ChemElectroChem 2020, 7, 3336-3340.

(22) Strietzel, C.; Sterby, M.; Huang, H.; Stromme, M.; Emanuelsson, R.; Sjodin, M. An Aqueous Conducting RedoxPolymer-Based Proton Battery That Can Withstand Rapid Constant-Voltage Charging and Sub-Zero Temperatures. Angew. Chem. 2020, 59, 9631-9638.

(23) Sterby, M.; Emanuelsson, R.; Huang, X.; Gogoll, A.; Strømme, M.; Sjödin, M. Characterization of Pedot-Quinone Conducting Redox Polymers for Water Based Secondary Batteries. Electrochim. Acta 2017, 235, 356-364.

(24) Sterby, M.; Emanuelsson, R.; Mamedov, F.; Strømme, M.; Sjödin, M. Investigating Electron Transport in a Pedot/Quinone Conducting Redox Polymer with in Situ Methods. Electrochim. Acta 2019, 308, 277-284.

(25) Milczarek, G.; Inganäs, O. Renewable Cathode Materials from Biopolymer/Conjugated Polymer Interpenetrating Networks. Science 2012, 335, 1468

(26) Admassie, S.; Elfwing, A.; Jager, E. W. H.; Bao, Q.; Inganäs, O. A Renewable Biopolymer Cathode with Multivalent Metal Ions for Enhanced Charge Storage. J. Mater. Chem. A 2014, 2, 1974-1979.

(27) Nilsson, T. Y.; Wagner, M.; Inganäs, O. Lignin Modification for Biopolymer/Conjugated Polymer Hybrids as Renewable Energy Storage Materials. ChemSusChem 2015, 8, 4081-4085.

(28) Navarro-Suárez, A. M.; Casado, N.; Carretero-González, J.; Mecerreyes, D.; Rojo, T. Full-Cell Quinone/Hydroquinone Supercapacitors Based on Partially Reduced Graphite Oxide and Lignin/ Pedot Electrodes. J. Mater. Chem. A 2017, 5, 7137-7143.

(29) Cíntora-Juárez, D.; Pérez-Vicente, C.; Kazim, S.; Ahmad, S.; Tirado, J. L. Judicious Design of Lithium Iron Phosphate Electrodes Using Poly(3,4-Ethylenedioxythiophene) for High Performance Batteries. J. Mater. Chem. A 2015, 3, 14254-14262.

(30) Das, P. R.; Komsiyska, L.; Osters, O.; Wittstock, G. Pedot: Pss as a Functional Binder for Cathodes in Lithium Ion Batteries. J. Electrochem. Soc. 2015, 162, A674-A678.

(31) Oka, K.; Murao, S.; Kobayashi, K.; Nishide, H.; Oyaizu, K. Charge- and Proton-Storage Capability of Naphthoquinone-Substituted Poly(Allylamine) as Electrode-Active Material for PolymerAir Secondary Batteries. ACS Applied Energy Materials 2020, 12019.

(32) Nantalaksakul, A.; Krishnamoorthy, K.; Thayumanavan, S. Broadening Absorption in Conductive Polymers through CrossLinkable Side Chains in a Nonconjugated Polymer Backbone. Macromolecules 2010, 43, 37-43.

(33) Karlsson, C.; Huang, H.; Strømme, M.; Gogoll, A.; Sjödin, M. Ion- and Electron Transport in Pyrrole/Quinone Conducting Redox Polymers Investigated by in Situ Conductivity Methods. Electrochim. Acta 2015, 179, 336-342. 
(34) Welsh, D. M.; Kloeppner, L. J.; Madrigal, L.; Pinto, M. R.; Thompson, B. C.; Schanze, K. S.; Abboud, K. A.; Powell, D.; Reynolds, J. R. Regiosymmetric Dibutyl-Substituted Poly(3,4Propylenedioxythiophene)S as Highly Electron-Rich Electroactive and Luminescent Polymers. Macromolecules 2002, 35, 6517-6525.

(35) Groenendaal, L.; Jonas, F.; Freitag, D.; Pielartzik, H.; Reynolds, J. R. Poly (3, 4-Ethylenedioxythiophene) and Its Derivatives: Past, Present, and Future. Adv. Mater. 2000, 12, 481-494.

(36) Yu, Y.; Gunic, E.; Zinger, B.; Miller, L. L. Spectra and Reactivity of Methoxyoligothiophene Cation Radicals. J. Am. Chem. Soc. 1996, 118, 1013-1018.

(37) Guay, J.; Diaz, A.; Wu, R.; Tour, J. M. Electrochemical and Electronic Properties of Neutral and Oxidized Soluble Orthogonally Fused Thiophene Oligomers. J. Am. Chem. Soc. 1993, 115, 18691874.

(38) Baeuerle, P.; Segelbacher, U.; Maier, A.; Mehring, M. Electronic Structure of Mono- and Dimeric Cation Radicals in End-Capped Oligothiophenes. J. Am. Chem. Soc. 1993, 115, 10217-10223.

(39) Oyaizu, K.; Ando, Y.; Konishi, H.; Nishide, H. Nernstian Adsorbate-Like Bulk Layer of Organic Radical Polymers for HighDensity Charge Storage Purposes. J. Am. Chem. Soc. 2008, 130, 14459-14461.

(40) Wakizaka, D.; Fushimi, T.; Ohkita, H.; Ito, S. Hole Transport in Conducting Ultrathin Films of Pedot/Pss Prepared by Layer-byLayer Deposition Technique. Polymer 2004, 45, 8561-8565.

(41) Oka, K.; Nishide, H. Radical Polymers for Rechargeable Batteries. Redox Polymers for Energy and Nanomedicine 2020, 34, 137.

(42) Choi, W.; Harada, D.; Oyaizu, K.; Nishide, H. Aqueous Electrochemistry of Poly(Vinylanthraquinone) for Anode-Active Materials in High-Density and Rechargeable Polymer/Air Batteries. J. Am. Chem. Soc. 2011, 133, 19839-19843.

(43) Oka, K.; Strietzel, C.; Emanuelsson, R.; Nishide, H.; Oyaizu, K.; Strømme, M.; Sjödin, M. Characterization of Pedot-Quinone Conducting Redox Polymers in Water-in-Salt Electrolytes for Safe and High-Energy Li-Ion Batteries. Electrochem. Commun. 2019, 105, 106489 .

(44) Chen, W.; Li, G.; Pei, A.; Li, Y.; Liao, L.; Wang, H.; Wan, J.; Liang, Z.; Chen, G.; Zhang, H.; Wang, J.; Cui, Y. A ManganeseHydrogen Battery with Potential for Grid-Scale Energy Storage. Nat. Energy 2018, 3, 428-435. 